\title{
Fernando González: caminando por su novela Viaje a pie*
}

\author{
FRANCISCO LUIS GIRALDO GUTIÉRREZ \\ Instituto Tecnológico Metropolitano de Medellín \\ franciscogiraldo@itm.edu.co \\ ANDREA MARÍA NUMPAQUE ACOSTA" \\ Universidad Pedagógica y Tecnológica de Colombia \\ andrea.numpaque@uptc.edu.co \\ DAVID ALBERTO LONDOÑO VÁSQUEZ \\ Institución Universitaria de Envigado \\ dalondono@correo.iue.edu.co
}

Recepción: 12 de diciembre de 2016.

Aprobación: 25 de marzo de 2017.

Forma de citar este artículo: Giraldo Gutiérrez, F. L., Numpaque Acosta, A. M., \& Londoño Vásquez, D. A. (2017). Fernando González: Caminando por su novela Viaje a pie. Cuadernos de Lingüística Hispánica, (30), 125-145. doi: https://doi.org/10.19053/0121053X. n30.0.6191

* Artículo de reflexión.

** Doctor en Filosofía de la Universidad Pontificia Bolivariana. Docente de la Facultad de Artes y Humanidades del Instituto Tecnológico Metropolitano de Medellín. Pregrado en Filosofía en la Universidad de Antioquia; Magíster en Filosofía Política de la misma universidad. Su trabajo de investigación está enfocado en la línea de «Filosofía de la Ciencia y la Tecnología», con énfasis en el problema de la Racionalidad Tecnológica. Instituto Tecnológico Metropolitano. Medellín.

*** Coordinadora Editorial de la Universidad Pedagógica y Tecnológica de Colombia, estudiante Maestría Literatura de la misma universidad; Licenciada en Educación Básica con énfasis en Matemáticas, Humanidades y Lengua Castellana de la Uptc.

**** Doctor en Ciencias Sociales, Niñez y Juventud de la Universidad de Manizales-Cinde, Docente de la Facultad de Ciencias Sociales de la Institución Universitaria de Envigado. Pregrado en Traducción Inglés-Francés-Español y Magíster en Lingüística de la Universidad de Antioquia, investigador de la línea Estudios Éticos, Estéticos y Comunicativos del grupo de investigación en Psicología Aplicada y Sociedad de la Institución Universitaria de Envigado. Researcher ID: F-8907-2013. ORCID: 0000-0003-1110-7930. 


\title{
Resumen
}

Fernando González, ícono de la tradición literaria antioqueña, ha hecho que hoy en día las profundas y polémicas ideas sobre la realidad de su época lo presenten como un escritor con alta sensibilidad social, política y un constante renegar religioso. "Caminar" por la obra Viaje a pie, es precisamente eso: recorrer los senderos que él transitó en un tiempo. En el presente artículo se busca conocer la concepción que el autor tiene sobre la geografía, el amor, el desamor, la familia, la política y la religión, procurando así una caracterización del pensador envigadeño, la contextualización de los hechos y escenarios presentes en la obra referenciada.

Palabras clave: política-religión-fanatismo, familia colombiana, sociedad antioqueña, amor y filosofía, conservadurismo-costumbrismo.

\section{Fernando González: Walking through his Novel Viaje a pie [Travelling on Foot]}

\begin{abstract}
Fernando González is a literary icon of Antioquia, Colombia. His deep and polemic thoughts on the reality of his times are the reason why he is now presented as a highly sensitive writer, regarding social, politic and religious aspects; the latter being the one he complains the most about. Reading his book Viaje a pie [Travelling on foot] feels just like "walking through" the paths he once travelled. This article seeks to comprehend the author's conception of geography, love and lovelessness, family, politics and religion, in order to characterize him, taking into account the context, events and situations presented in his novel.
\end{abstract}

Key words: Political and religious fanaticism, Colombian family, Antioquia society, love and philosophy, conservatism and costumbrismo. 


\section{Fernando González: En marchante par son roman Voyage à pied}

\section{Résumé}

Fernando González, icone de la tradition littéraire d'Antioquia (en Colombie), a fait qu'aujourd'hui les profondes polémiques idées sur la réalité de son époque, le présentent comme un écrivain ayant une grande sensibilité sociale, politique et un constant renié religieux. « Marcher » par l'œuvre Voyage à pied, est précisément cela: parcourir les sentiers qu'il a parcourus à un moment donné. Dans cet article, on cherche à connaître la conception que l'auteur a sur la géographie, l'amour, le désamour, la famille, la politique et la religion, en veillant ainsi à une caractérisation du penseur d'Envigado (son lieu d'origine), la contextualisation des faits et des scénarios présents dans l'œuvre référenciée.

Mots clés: politique-religion-fanatisme, famille colombienne, société d'Antioquia, amour et philosophie, conservatisme-peinture des mœurs.

\section{Fernando González: caminhando por sua novela, viagem a pé}

\section{Resumo}

Fernando González, ícone da tradição literária antioqueña, fez que, hoje, as ideias profundas e polêmicas sobre a realidade de seu tempo para apresentá-lo como escritor com alta sensibilidade social, política e uma queixa religiosa constante. "Caminhando" pela novela viagem a pé, é precisamente isso: caminhar pelos caminhos que ele transitou há algum tempo. Neste artigo, busca-se a concepção do autor sobre geografia, amor, família, política e religião, buscando uma caracterização do pensador envigadeño, a contextualização dos fatos e cenários presentes no Trabalho referenciado.

Palavras-chave: política-religião-Fanatismo, família colombiana, sociedade de Antioquia, amor e filosofia, conservadorismo - costumbrismo. 


\section{A modo de introducción}

Interpretar lo acontecido en la obra Viaje a Pie de manera literaria no es sencillo, es parecido a querer caminar sin antes siquiera gatear o haber gateado; hablar de lo que no se sabe; develar lo oculto; deambular en el claro horizonte, fino y sobriamente delineado por un buen pintor de las letras, un expresionista de la vida, de la naturalidad, del sentimiento libre de ataduras, máxime cuando el artista es reconocido por lo profundo de sus pensamientos, y polémico y futurista de sus ideas. En palabras de Peñuela (2010), "Fueron precisamente la libertad de pensamiento, el agudo lenguaje y la irreverencia escritural que lo caracterizaron, los que generaron afiladas críticas por parte de sus detractores en torno a sus radicales posicionamientos" (p. 201), que se evidencia en Viaje a pie, obra que deja entrever la intención y composición del autor.

Recorre los caminos de pensamientos imbricados en las montañas antioqueñas; como los molinos de viento que le son revelados a Don Quijote, gigantes, vistos por él y a los cuales debía combatir para rescatar a su amada Dulcinea. Viaje a pie se presenta como aquel oasis cálido y fresco, a veces angustiante, que convoca a hacer altos en el camino, para asumir lo cotidiano, lugares en los que él y el paisaje se convierten en un solo ser, y en el que se mantienen presentes los pensamientos del hijo de Envigado.

Es así como se ha pretendido ubicar a autores que hayan trabajado la obra de este autor, que posibiliten un asidero claro, pero la búsqueda ha sido poco pertinente. Buenas intenciones con resultados poco favorables. No obstante, y en ese mar de sinsabores, se desarrolla, sin ningún criterio metodológico, un análisis contextual de algunos de los posibles conflictos que en la fértil propuesta filosófica se hace evidente en esta obra.

Como elementos de juicio para llevar a cabo el análisis de la obra Viaje a pie, se parte de elementos de hermenéutica literaria, en especial de corte histórico, político y cultural. Se tienen presentes algunas ideas que, sobre Fernando González, presentan autores como Gonzalo Arango (1993), Javier Henao Hidrón (1993), Germán Pinto Saavedra (1995), Fabio Villegas Botero (1995) y Luis Fernando Macías Zuluaga (1996), ideas que si bien de la mayoría de ellos no se hacen referencias directas en el presente artículo, sí orientan el desarrollo del mismo. 
Las temáticas desarrolladas a partir de la obra Viaje a pie, son contextualizadas y problematizadas para develar las posiciones que González asume frente a varios tópicos trabajados en el presente escrito.

La pretensión, entonces, es la de dar cuenta de cuatro aspectos, aunque sin la intención de excluir los otros temas que están presentes en la obra referida. Tales temas son: Sobre el pensar o el filosofar; Amores, nunca desamores; Conservadurismo y religiosidad en Fernando González; Conclusiones y convergencias.

\section{Sobre el pensar o el filosofar}

Fernando González posibilita un filosofar desde la distancia a tiempos de hoy, su presencia ya es lejana pero sus pensamientos, su filosofía, siempre estarán presentes. Se le reconoce como el hombre que "hablaba de la realidad de cada día, de lo que estaba sucediendo, de los personajes que hicieron la historia y de los que mangoneaban la realidad de su tiempo con nombres propios y apellidos, en el lenguaje que todo el mundo usaba" (Ochoa, 1995, p. 101). Su modo de vida es intenso, vivió la cotidianidad de su tiempo con pasión y angustia. Desde el diario vivir, se acude a la historia, la política, la cultura y la religión como excusa para el pensar y el filosofar. González se autonombró filósofo, y en Viaje a Pie es claro que es un filósofo en formación: "Nos llamamos filósofos aficionados para no comprometernos demasiado y porque ese nombre es mucho para cualquiera" (González, 1995, p. 2). Hay un respeto por el filósofo y, en general, por el conocimiento. Al respecto, agrega:

En los manuales de filosofía, lo primero que se explica es aquello de que filósofo quiere decir amigo de la sabiduría; se enseña allí, en las primeras hojas, a descomponer la palabra en philos y en sophos, con lo cual el estudiante imberbe cree que sabe griego y les repite eso a las primas, junto con aquello que decía Sócrates en los alrededores de la Acrópolis durante sus noches de moralizador: "Sólo sé que nada sé" (González, 1995, p. 2).

No se aprende a filosofar por decreto, es un ejercitar permanente de la razón a partir de lo que se piensa y la aproximación a lo que se conoce o desconoce es el camino a la construcción de conocimiento. Hay quienes plantean que no hay verdades absolutas, tampoco verdades a medias, solo modos y condiciones de aproximación al objeto-cosa, es la pugna por quien tiene la verdad sobre el objeto, generada entre las distintas escuelas de pensamiento.

En América Latina, el peso de la evangelización española ha dejado su manto de desidia cultural y de desarraigo territorial. A partir de la conformación oficial, hacia me- 
diados del siglo XIX, los partidos políticos tradicionales en Colombia: liberal y conservador, han tergiversado la realidad de una nación y desvirtuado la identidad de un pueblo. La falta de conocimiento de la historia lleva al pueblo a cometer atrocidades políticas, a desconocer las potencialidades de desarrollo social y económico. Como desmanes políticos se cuentan aquellos a los que se refiere González sobre los hechos de finales de siglo XIX y comienzos del XX:

Comenzaron vendiendo a Panamá y hoy está casi todo está vendido. Ya Colombia no hace versos. A la sombra del Simón Bolívar atormentado de las plazas públicas, a la sombra de las iglesias y sirviendo de moneda la cara angulosa del Libertador, se reparten los dineros. No tenemos ideas; no tenemos sino opiniones; de vez en cuando hacemos un soneto a Cristo Rey y por ello nos envían como diputados (González, 1995, p. 34).

La historia ha mostrado que la doctrina religiosa con la que los españoles vinieron a Colombia no fue cuestionada, no se confrontaron creencias naturales, las de los indígenas precolombinos y la evangelización que recién comenzaba en el siglo XV. Igual pasa con la política y los políticos, al pueblo nunca le toca, elegimos para que administren las riquezas de una Nación y generen bienestar y desarrollo para los ciudadanos, pero los políticos, se preocupan exclusivamente por el aumento de su capital y el pueblo, aguanta y protesta cuando se lo permiten, desarrollando una alta sensibilidad sobre los problemas de su época, aunque con poca posibilidad de cambio. El pensador envigadeño añora la creatividad y la lúdica, resalta la calidad de la producción literaria de los colombianos, en la que se recrean los hechos y se realizan las mejores críticas a personajes reales, pero representados en la obra literaria; ese ensueño idealizado que se hacía evidente en la poesía y la literatura de finales del siglo XIX y comienzos del XX:

El problema de los pueblos aparece iluminado por ese concepto de nuestra vieja. Cuando se agota la energía de la raza, aparecen los predicadores de la paciencia y demás parásitos. Grecia nos da un ejemplo cuando, al decaer, apareció aquel tábano sobre el caballo Atenas: Sócrates. Contaba él mismo que un frenólogo le dijo que su cabeza era el nido de las malas pasiones. Sócrates, feo y frío, lógico como un serrucho, tolerante y descreído, apareció cuando se acabó al ánimo griego. Surgió la moral, ese chorro inicuo de frases que sale de las bocas sin dientes. (González, 1995, p. 12).

En el momento que Fernando González en Viaje a pie, habla de la figura socrática y los ideales de esta, pone en evidencia la decadencia en la que está sumida la cultura occidental que el mismo Sócrates promovió. En el plano de la literatura, añora los periodos en que Colombia era reconocida por la calidad y cantidad de su producción literaria: 
Colombia fue el país de la literatura hasta por ahí al final del siglo [xix]. Un soneto era entonces lo que es hoy para un joven exministro el ser agente de la casa Halle Garten. Era el tiempo de nuestro apasionamiento; fue el tiempo del idealismo. [...] jQué almas tan apasionadas aquellas de la Colombia liberal!; era un país digno y heroico. Fue la del sesenta y tres una Constitución que admiró por su idealismo a Víctor Hugo. [... ]iPero en todo hemos sido desarmónicos! Un sátiro de Cartagena dio principio a la descomposición moral (González, 1995, p. 33).

De igual manera, y con un tinte político, González deja ver que en esa producción literaria está presente el alma y el espíritu libre de su ser. Los espíritus geniales producen, crean en libertad, desprendidos de la geografía y con mentalidad tranquila. El bombre nace libre y la sociedad lo corrompe, decía Rousseau, es la sociedad quien enjaula los espíritus libres y las mentes brillantes, estas se muestran rebeldes y en ocasiones agrestes como una muestra de sublevación por su libertad. El alma libre es capaz de generar obras geniales: la producción artística requiere de largos períodos de ocio para propiciar espacios que permitan ver la luz de la ilustración, pensar y expresar ante la comunidad dejando de lado la vegetación del espíritu, la ruina y la miseria del pensamiento.

Cuando se habla de la capacidad de pensar, como condición propia -aunque no exclusiva del filósofo- del filosofar, de manera implícita está el asunto de la ciencia, el método, el sujeto que piensa, el objeto conocido o por conocer. En el momento en que se piensa, se pregunta por el objeto, hecho, fenómeno. El pensar-filosofar en González contextualiza las variables que embargan la presencia del objeto: tiempo, espacio, tamaño, forma, materia, utilidad y finalidad, es lo determinante en la acción de pensar. De entrada, al respecto propone: "Nunca se debe meditar a un tiempo en más de una cosa, y sabe la fuerza de un alma metodizada, concentrada, cuando en el momento dado lanza su deseo y su pensamiento hacia un fin determinado" (González, 1995, p. 26). Nos inscribimos desde las características y condiciones de nuestros pensamientos en una escuela, una doctrina, un área del conocimiento; de este modo:

Cada ciencia que se posea es una ventana más para contemplar el mundo. Así, el viajero que sea botánico, gozará de la vegetación; el mineralogista, etc. El hombre de ideas generales, como nosotros, goza de todos los aspectos, pero con la desventaja de la disminución de cada uno de ellos (González, 1995, p. 6).

La posibilidad de racionalizar, tal como lo propuso Descartes, en su Discurso del método y su duda metódica, posibilita superar el conocimiento meramente empírico, sin experimentación-comprobación de las manifestaciones de los hechos-fenómenos. Es así como se observa que a Fernando González le preocupa la sociedad de su tiempo, y la herencia futura, situación que, en su condición de pensador, valida sus pensamientos más 
allá de su tiempo, todavía hoy en el segundo decenio del siglo XXI. "Llegar a ser un hombre propio para los fines que indican el tiempo compuesto de segundos y la tierra compuesta de frivolidades venales" (González, 1995, p. 27). Critica la educación de su tiempo por considerarla dogmática, anquilosada en unos métodos poco liberadores y progresistas para la juventud.

Desde la modernidad y hasta la ilustración, el hombre se dejó deslumbrar con el método científico y el desarrollo de la ciencia experimental, cayendo postrado a los pies de esta. Es la ciencia la que le hace el milagro al hombre, el milagro de prolongarle su tiempo de permanencia (su tiempo de angustias y crisis existenciales) en este mundo; la edad, el tiempo, son inconmensurables, implacables, no se detienen; aun después de muertos se les lleva el tiempo a los muertos, se cuentan los días, meses y años. Estando vivos, los hombres modernos, después de cierta edad, viven angustiadamente por el transcurrir imparable del tiempo:

El hombre, cuando llega a los treinta años, a esa cima dorada, principia a anidar filosóficamente. Dicen que en el niño se remplazan completamente en un año las células que componen su organismo, y que ese renovarse es lento en el hombre maduro y desaparece casi completamente en el viejo. Lo mismo pasa con las ideas y emociones. iQué más dogmático que un anciano! A los treinta años el hombre adopta una filosofía (González, 1995, p. 10).

El hombre contemporáneo es reconocido por la cantidad de dinero que posee, el ideal es estar arrodillado ante el dios dinero. La riqueza material es lo que se valora desde la Revolución Industrial; los ideales metafísicos y la condición existencialista del hombre, sucumben en la sociedad capitalista. Sin embargo:

Nadie goza sino nuestro joven metódico que usa de las cosas y no se deja poseer por ellas. Siempre que el hombre llega a ser incapaz de prescindir de algo, se hace esclavo de ello y disminuye su poder. Es preciso en toda circunstancia, en todo momento, aun ante la mujer más hermosa, poseerse a sí mismo (González, 1995, p. 25).

El joven consumidor de hoy, que es el pensado por González en la tercera década del siglo XX, sortea el nefasto juego que la sociedad de consumo le impone. González avizora en el hombre de su tiempo, lo metódico que deber ser el hombre en el futuro. En este mundo de banalidades, de apegos, hay alguien que lucha por liberarse de ese mundo. Alguien que se niega a la pérdida de su condición humana, atravesada por las pasiones, los sentimientos: el joven pragmatista. Sobre este tema, González (1995) puntualiza: 
El joven pragmatista no ama el dinero por instinto, de nacimiento, por decirlo así. Nosotros no admiramos ni predicamos a favor de los avarientos sin estética, sucios, innatos. [...] El joven pragmatista pretende saber cómo se reúne una gran fortuna y cómo se vive una gran vida. El joven pragmatista admira lo único que hay de admirable en este esferoide: EL MÉToDo, la capacidad de perfeccionarse que tiene el hombre; la Ló-GI-CA (p. 26).

El pensamiento lógico exige que nos neguemos a sentir, a disfrutar de las mieles del amor, de nuestro ser pasional, que por regla se nos han concedido. Como lo plantea Feyerabend en Contra el método, de las pasiones y los sentimientos también se aprende. Para conocer, no basta con una razón absoluta, la razón por la razón, la razón instrumental. La razón como medio y fin y no como posibilidad. La razón matematizada ha llevado el sentimiento y las pasiones del hombre, a cuadrículas representadas en el plano cartesiano. La razón absoluta ha frustrado al hombre en el momento de identificar y cultivar sus pasiones. Para el joven pragmatista, los referentes son otros, se la juega a una cosa a la vez. Es por esto que:
Nosotros, siguiendo el ejemplo de los grandes amantes, no amamos sino a una mujer en cada tiempo; nosotros, el joven pragmatista, siguiendo el ejemplo de los grandes pensadores, no pensamos sino en un problema a cada tiempo, y siguiendo el ejemplo de los grandes activos, concentramos nuestra actividad en nuestra obra: el dinero, representativo de todo lo terreno (González, 1995, p. 26).

El hombre culto que presenta González, es el referente diferenciador que se ha sublevado, que ha visto en la razón el instrumento, como punto de partida, no como fin último, para liberarse del yugo del dogma religioso que por siglos se le ha impuesto. El bombre culto se libera de los dogmas de fe. González lo concibe como un ser inacabado, totalmente insatisfecho e inquieto con lo que ha conocido, pero de igual modo consciente de lo mucho que le falta por conocer. Es así que:
El psicólogo, por ejemplo, tiene su ciencia como un núcleo que da el colorido a toda su formación mental, que es todo y que aprehendería el hombre por intuición, si fuera infinito, podemos compararlo con una circunferencia cuyo centro esté en todas partes. Así, es centro de la infinita realidad cualquiera ciencia o cualquier propósito; desde ellos se llega a percibir una remota vislumbre de lo infinito (González, 1995, p. 35).

El conocimiento, la sabiduría, es el eje articulador, transversal a toda acción del hombre. El radio de acción del hombre culto es el centro mismo del círculo, de la esfera, con la particularidad que eso que piensa y hace o deja de hacer el hombre culto, lo acompaña en el presente y futuro. 


\section{Amores, nunca desamores}

En este viaje nos alistamos a reflexionar sobre uno de los temas más trabajados en la literatura desde La Ilíada: el amor, los afectos y sentimientos, el padecimiento del estar enamorado. Los sentimientos son una fuerza tan grande, las pasiones como las establece Espinoza -cuán inexplicables-, y, como el amor, enceguecen, idiotizan, pero siempre nos obligan a seguir padeciendo: la necesidad, el deseo de amar y ser amado es lo que envuelve la condición de la vida humana, lo que le da sentido y valor a lo que a diario hacemos por alcanzarlo. Como bien lo han planteado Platón en diálogos como El Banquete o en Fedro, Aristóteles en Ética a Nicómaco y Ética a Edudemo; Ovidio en El Arte de amar, Bocaccio en los relatos del Decamerón y Kant en Lo sublime, lo bello y sus formas.

El pensar con la razón no está en el amor, un amor racional es un amor de la utilidad y la finalidad -fines y medios-, meramente estético, de ideales materiales, de cánones de belleza promovidos en la sociedad de consumo. Dada la naturaleza humana, en muchas circunstancias el amor supera la razón. La razón es opacada, relegada, es esclava del amor.

Del amor y el estar enamorado, se dice y se representa, pero como aproximación mínima a lo que es amar y ser amado; como estado metafísico, el amor se vive, se disfruta y padece -el desamor o engaño amoroso- pero no se experimenta en un tubo de ensayo o se reproducen modelos en las grandes industrias. Como se dirá con González en la siguiente cita, en las sociedades contemporáneas y altamente industrializadas el amor es el negocio esencial:

iEl amor! Todo él está en los ojos y en los actos. ¿Para qué sirve la palabra allí? Una mujer quiere a un hombre: ¿que el padre morirá? Que muera; ¿que resulta el fin de todo? Que venga ese fin. [...] es que el amor es el negocio esencial-; el afecto filial, el sentimiento de honor, las ideas, son accesorios lujosos, lo mismo que los pétalos: lo esencial es el pistilo y el estambre (González, 1995, p. 16).

Los pétalos son la manifestación material y la apariencia estética del amor, lo determinante del amor no solo es lo que es y cómo se manifiesta, un asunto de racionalidad cognitiva que se ha planteado en el numeral anterior, sino realmente lo que lo convoca y provoca: el pistilo y el estambre. Todo en el hombre es pasión y razón, lo primero desde el sentir del mismo hombre, lo segundo como elemento del pensar. El amar, el estar enamorado y sentirse amado es el ideal de todo humano, la razón le pone límites a las pasiones humanas. 
El transcurrir de los días, meses y años en cada sociedad es propio de su tiempo, son las mismas sociedades quienes le ponen ritmo a sus actividades diarias. Hay sociedades como las macondianas, bien descritas y contextualizadas por Gabriel García Márquez en Cien años de Soledad, en las que el tiempo no pasa, pareciera como si cada nuevo día fuera el mismo; pero también existen ciudades como New York, Sao Paulo, Tokio, Taiwán, Singapur, en donde sus habitantes están en una lucha constante contra el tiempo, su vida transcurre en un afán desaforado por llegar a... y cuando escasamente se está llegando al lugar A, ya se está pensando cómo poder llegar al lugar B. Solo el amar y ser amado frena por momentos recurrentes el tiempo, el ritmo es el del amor, que de por sí carece de él. Vemos que en el andar enamorado por la vida:

Cada individuo tiene su ritmo para caminar, para trabajar y para amar. Indudablemente cuando un hombre y una mujer se atraen, eso se verifica por sus ritmos; es porque unidos son importantísimos para la economía del universo. Por el ritmo podrán clasificarse los hombres (González, 1995, pp. 3-4).

El camino del amor, aparte de espinoso, es empinado. Ese camino ya no solo "es culebrero", sino también incierto. El amor es uno de los dioses más antiguos, lo dice Fedro en el diálogo de Platón, pues no se le conocen sus padres, ni poeta alguno se atribuye su creación. Los hombres modernos han olvidado ver lo bello en formas mínimas, lo bello en lo simple y sencillo; fantasean con ideales artificiales, creados y vendidos por un sistema de consumo, que como estrategia de mercado, renueva permanentemente necesidades. Frente al amor, y la belleza de un cuerpo femenino que inspira no solo deseo, sino ser amado, quien ama se queda con la sensación que dejan las siguientes líneas:

Pensamos que la belleza es la gran ilusión; pensamos que la naranja es una esfera de oro, y que para comérsela se tira la corteza dorada. iAquellas faldas prensadas! ... Pero no; nosotros no queremos describir lo que pasaría si fuéramos a comernos aquel fruto de altiplanicie andina. No queremos describirlo, porque podrían acusarnos de corruptores de la juventud, como lo hicieron con el maestro Sócrates (González, 1995, p. 7).

Es el amor un ideal materializado en un objeto de deseo, de engaños y desengaños, sabores y sinsabores. El amor da lugar a los más dulces poemas, al reconocimiento de la pequeñez frente a lo grande, a lo inmenso. El amor fugaz, de ocasión, es propio de nuestro tiempo, ya no permanece la idea, la necesidad de idealizar el amor, ni el objeto a amar, más aún, el objeto de deseo. Pero, de igual forma, al amor y al ser amado no se les perdona, no se les acepta la rutina, la monotonía, la falta de creatividad y la ausencia de autonomía: 
Y por eso, porque no tenemos ideas sino opiniones, porque no hay eternidad, porque no hay sino un pequeño manojo de segundos y un pequeño manojo de emociones, [...]. ¿Qué cosa más horrible para nosotros que una mujer constante? Es como una idea fija; es como un vestido que uno no se pudiera quitar. El encanto de la vida; ¿pues qué será de la vida y del amor a ella si no supiéramos que íbamos a morir? (González, 1995, pp. 20-21).

El amor, el amar es un copular permanente, con la otra, con el otro, con sí mismo: "Así es el amor. Vencimiento del amante y triunfo del amado. Era la vida que encerrabas tú, era tu ánimo lo que se imponía a nuestra pobreza, y por eso te ansiábamos como el agua en el desierto" (González, 1995, p. 11). Quien cree que en el amor no hay vencedores ni vencidos, cuán engañado está. Al final no solo se disfruta de las dulces mieles a que la hembra da lugar, sino que también en muchos casos se corre el riesgo de terminar muerto por su ponzoña. El amor y el acto amoroso adquieren el estatus de tragedia:

¡Cuán trágico en el amor el papel representado por el macho! Damos vueltas y revueltas alrededor de la amada. La hembra, quizá porque solo es amada mientras es deseada, va alargando el asedio. Ved los escorpiones, cómo se pasean días y días cogidos por sus palpos; el macho de la araña que se acerca a ella tembloroso, se devuelve y espera durante días el momento propicio, si es que antes no es devorado por ella. La hembra dirige el amor y lo dirige de un modo lento, saboreado (González, 1995, p. 29).

El amor que se genera en el deseo y desde él es fútil, baladí: es una falacia, por esto el joven vive a plenitud su juventud, vive sin apegos, sin dependencias hacia el otro (a) y el viejo vive de lo vivido, de lo valioso y significativo que ha realizado en su vida, como bien caracteriza González la condición del viejo: "Así, pues, siempre es la fuerza vital la que domina. En todas las manifestaciones de este vivir, triunfa la energía descubierta por el doctor Mesmer; va recorriendo el tiempo y riéndose de todo...” (p. 11). Lo que hace interesante al amor, cuando no está supeditado a la forma, a la materialidad del objeto amado, es que permanece, se hace eterno, está siempre presente aunque adquiera otros niveles e intensidades. Cuando hay un deterioro del ser, de la persona amada, iacaso decae el amor, el ideal, la búsqueda del mismo? ¿Quedaremos, como lo plantea González, en un epifenómeno?:

Caen mis cabellos y mis dientes se amarillean, crecen las niñas y crecerán otras, y vendrán amaneceres, atardeceres, soles y cielos esplendorosos. iMis cabellos, entonces, idos, y mis dientes amarillentos! iQué epifenómeno es mi vida! iQué bagatela, tan efímera y deseable, la belleza! No hay más remedio que irse agarrando a un propósito que nos escude contra la tristeza de la decadencia y la muerte (p. 13). 
El viejo en Fernando González se siente incapaz de responder a las bondades del amor, a los momentos de erotismo y perversión que posibilitan el ser afectivo del hombre. Los ideales de edad cronológica parecen haberse perdido, de igual manera los cánones de belleza parecen haber cambiado, evidentemente a pesar de lo futurista de los pensamientos de González, en esto se ha quedado corto, no visionó que el desarrollo de la ciencia y la tecnología podían generar un cambio en las relaciones afectivas del siglo XXI.

Conjugando el tiempo cronológico en el hombre con los asuntos del amor, podemos ver que el cuerpo se deteriora, se descompone, las bellas formas, otrora bien proporcionadas, han desaparecido, que la capacidad de responder a la intensidad del acto pasional disminuye, el hombre se va reduciendo a un epifenómeno: "iPor qué, si soy un vulgar y despreciable epifenómeno, esta tristeza? ¿Por qué florecen árboles y florece la belleza femenina, y sigue el devenir, y yo me quedo, me voy muriendo?” (González, 1995, p. 13). La realidad para el hombre viejo, es que mientras hay una disminución en la capacidad de ser, hacer y sentir, las cosas en su alrededor avanzan, el tiempo parece ser más lento, detenerse para los demás y acelerarse para el viejo. Hay una angustia del ser, una pregunta por el existir y desde él, por la condición humana; eso es el hombre: nacer, crecer, reproducirse, envejecer y morir. El hombre en su naturaleza pasional no renuncia a la posibilidad de beber del manantial del amor y los beneficios que el culto a Eros posibilita, se niega a que su ser pasional y cargado de afecto desaparezca, aunque: "Por momentos quisiera destruir lo bello.... iDeseo horrible del que decae, del hombre que envejece y que no admite el hecho, la posibilidad siquiera, de que haya belleza que no sea suya y que siga el vivir después de su muerte!" (pp. 13-14).

Con relación al amor, los desamores y la mujer en general, González plantea doce conclusiones que, a la larga, serán máximas por seguir en estos rodajes amorosos. Las conclusiones promovidas, si bien son todas producto de las reflexiones sobre los contextos de su época, es claro que se debe tener cuidado al momento de aplicarlas, de modo analítico, a situaciones de comienzos del siglo XXI. Somos circunstanciales, pero nada finitos; por naturaleza, en estas cuestiones afectivas, somos instintivos, impulsivos; se deben dejar cosas por descubrir y sentir; la moralidad y la castidad van en contra de la intención de un acto lujurioso, de la manifestación en acto del sentimiento de deseos hacia la mujer que provoca, que incita desde su ser. La razón, racionalizar sobre si se realizan o no las acciones afectivas, le resta interés a las mismas. Hay momentos de seducción, de conquista, que solo son de ese momento y no se presentarán en ningún otro tiempo, con la misma persona u objeto de deseo. Justificar la intencionalidad de nuestros actos daña la magia del momento y el encanto del actuante. El príncipe azul se desvanece, se distorsiona ante los prejuicios, ante el pensar en el qué dirá, qué pensará, cómo lo tomará. 
La añoranza siempre presente evidencia cuán importante es el amor para Fernando González; pero, de igual manera, en qué se centra, qué le inspira el tema del amor y el desamor. Frente al amor, González reconoce la posibilidad del desamor, como el desengaño 0 la frustración por lo no alcanzado. El desamor y desengaño amoroso es la evidencia clara de la conjugación del declive del hombre, es el reconocimiento de cuánto duele sentir y saber que esas bellas formas; juveniles, frescas, cual frutos de una huerta casera, ya son pasado:

Nuestras necesidades se han multiplicado; nuestros placeres son tantos como nuestros segundos... iSon tantas las mujeres hermosas y tantas las bagatelas que adornan sus cuerpos transitorios... y todo se vende. La moneda o, mejor dicho, el billete, es la piel mágica en que se viaja por países feéricos; iel billete es la imagen de todo lo agradable! (González, 1995, p. 22).

El amar también es posesión, como acción egoísta y por tanto equívoca, sobre lo amado se cree tener un título de propiedad y la titularidad cree tenerla quien ama y no el amado. Si bien nunca ba sido mía, ahora, con el pasar y el peso de los años, solo me queda saber que otro tendrá la posibilidad. El remordimiento es la sensación que queda tras una acción malintencionada, o por no haber hecho aquello que era conveniente. En un círculo hermenéutico, bajo un clamor por la juventud pasada y el deseo insatisfecho, vemos como:

Tú, futura muchacha de quince años, frívola como el espíritu y como el agua, [...] tú, grácil muchacha, pasarás tu mano larga y llena de fuego latente como el centro de las esferas celestiales, pasarás tus afilados dedos por los suaves cabellos de mis descendientes. iYo quisiera asesinarte, hermosa y futura muchacha! [...] En verdad que esto de envejecer, esto de llegar a los treinta y tres años, es una burla sangrienta que nos hace el tiempo, esa suprema necesidad (González, 1995, p. 14).

La añoranza del antes, del ahora y del siempre, solo quedará en la posibilidad de quienes nos anteceden; posiblemente sustenten lo acá planteado y darán cuenta de esos objetos de deseo. En la muchacha de quince se conjugan sentimientos encontrados y prohibidos, perversiones ocultas: "Porque, así como el delito, el amor tiene circunstancias antecedentes, concomitantes y consiguientes. Todo lo agradable de la vida es antecedentes del amor; todo lo que llamamos alegría, en cualquiera de sus manifestaciones, es antecedente del amor" (González, 1995, p. 19). En el amor todo se vuelve causa y efecto, principio y fin, como relación de causalidad. El hombre viejo, aquel que ha trasegado los caminos del amor y lo ha hecho de manera intensa, sabe muy bien que a su edad no puede desperdiciar energía corriendo alocadamente tras el ser amado; aun así: 
Las mujeres que han de servirnos de almohada, las que han de llorar por nosotros, vendrán a buscarnos en donde estemos, si han de ser nuestras. ¿Para qué correr tras ellas? Vendrá también el oro que ha de ser nuestro, y vendrá a esta dura piedra, el escondrijo más oculto, la muerte, y vendrá el deshonor, el dolor y el odio. ¿De qué huimos? ¿Para qué escondernos? [...] nadie nos pide cuenta y a nadie se la pedimos. Somos el que puede afirmar: el hombre tiene lo que merece; no tendrá lo que no merece. Venga, pues, a cada uno lo suyo (González, 1995, p. 31).

A su tiempo, modo y medida, a cada ser humano le llega lo suyo, el hombre en su tiempo de juventud siembra y riega el amor que ha de recibir en su vejez. En tiempos de vejez es cuando se alcanza la felicidad, esta es un camino que el hombre camina acompañado del amor, si no lo hace de esta manera, corre el riesgo de extraviarse. El amar y ser amado, como bien lo plantea Ovidio en el Arte de amar, es un acto desinteresado que no se lleva a cabo a la ligera; el estado de enamoramiento da lugar a que cada hombre se desprenda de máscaras, que se libere de prejuicios ante el otro.

Sobre el amor, Fernando González añora figuras de bellas mujeres e idealiza otras, en momentos de descanso en su Viaje a pie, sirviendo para concluir que el amor es un estado de sinsabor permanente, es una condición para explorar y experimentar en el otro y con él, un éxtasis constante, nunca un desengaño permanente, que se explora a través de su cuerpo, de sus sentimientos, y lo lleva a un plano creativo para encontrarse con la escritura que está en circulación en su interior y lograr identificar "ese lugar neutro, compuesto, oblicuo, al que va a parar nuestro sujeto, el blanco - y- negro en donde acaba por perderse toda identidad comenzando por la propia identidad del cuerpo que escribe" (Barthes, 1987, p. 65) para dejarse llevar por el sentimiento del amor, de la pasión, de la entrega, del sufrimiento, de la sensualidad y plasmarlo en cada una de sus líneas sin temor, sin castigo, sin duda.

\section{Conservadurismo y religiosidad en Fernando González}

Las cosas en tiempos de hoy, donde los modos de vida, los ideales y propuestas de tipo religioso, político, cultural y económico, marcan las características del futuro planteadas por González en las primeras décadas del siglo XX. Su habilidad literaria y sensibilidad posibilitan consolidar un entendimiento claro y objetivo de los hechos de su tiempo; "La paciencia, la contención, todas las antiguas virtudes de nuestros gordos antepasados, se predican a la juventud, pero no ya como virtudes, sino como métodos. La moral es pragmatista. Se aceptan las virtudes de los viejos tratadistas, pero porque son útiles" (González, 1995, p. 23), como manifiesta igualmente Barthes (1987): 
escribir, hoy en día, es constituirse en el centro del proceso de la palabra, es efectuar la escritura afectándose así mismo, es hacer coincidir acción y afección, es dejar al que escribe dentro de la escritura, no a título de sujeto psicológico..., sino a título de agente de la acción (p. 31).

En palabras de Ochoa Moreno, González fue un renegado de su tiempo, un inconforme que ve en la cotidianidad de sus días, en el andar de las montañas antioqueñas, el aliciente por el cual ser agudo en su análisis y mordaz en la crítica de la realidad de su tiempo y lo premonitorio de los tiempos futuros. González se caracteriza por ser quien

[...] se enfrentó a la mentira colombiana, y sus contemporáneos no le perdonaron la franqueza con que habló. Por eso fue excomulgado y olvidado. Y sin embargo, su verdad, que golpea y azota en sus libros, está aún tan viva que ha cobrado vigencia con el correr del tiempo (Ochoa, 1995, p. 99).

Con relación a lo religioso, González plantea desde el inicio de Viaje a pie: "Habíamos principiado este diario: "sonaban en la vecina iglesia, melancólicamente, las cinco campanadas...", y borramos eso porque eran reminiscencias del estilo jesuítico de nuestro maestro de retórica, el padre Urrutia" (González, 1995, p. 2). Con un tono de rechazo, de negación a un tiempo pasado, a un dogma siempre recalcado en sus tiempos en el seminario. Demuestra una sublevación y subversión a los cánones de un pensar y una escritura monotemático, tradicional y poco dinámico.

De esta manera, González mantiene una escritura libre de ataduras religiosas 0 de imposiciones que la misma sociedad creía debía respetar, su relato, siempre libre y decorado con la naturalidad que le caracterizaba o mejor en palabras de Foucault (1996):

La sencilla experiencia que consiste en coger una pluma y escribir desprende [...] una distancia que no pertenece ni al mundo, ni al inconsciente, ni a la mirada, ni a la interioridad, una distancia que, en estado desnudo, ofrece una cuadrícula de líneas de tinta y además un encabalgamiento de calles, una actividad naciente (p. 174).

Esa actividad naciente en González fue permanente, invita y provoca su lectura, entrañando en uno mismo el deseo por recorrer sus caminos, sus andaduras, sus pasos para identificar lo que con sus palabras y visto por sus ojos expresaba en cada línea.

La Compañía de Jesús llevó a Fernando González a pensar en su condición de hombre mortal, a comprender que el padecimiento en su forma individual y colectiva es una muestra de rebeldía, de renuncia a aquella idea de fe y dogma católico que le había sido inculcado. González, al igual que Nietzche en El Anticristo, provoca la muerte de un Dios cristiano y da la libertad de crear un nuevo Dios, El superhombre nietzcheano o Un Dios 
totalmente humanizado, que de manera traslapada añora González en su obra; el Dios humanizado padece las necesidades de hombres terrenos y disfruta de las mieles del amor. De acuerdo con esto, con González (1995) se precisa que:

Pero antes de seguir, y para que el libro se amolde a la definición que nosotros hemos creado, después de inspirarnos en el padre Ginebra, a saber: "organismo ideológico impreso", diremos cuál será este viaje a pie, cuáles sus finalidades, cuáles sus motivos y cuál el efecto pragmatista que nos proponemos al escribirlo y al darlo a la estampa. El reverendo padre Urrutia jamás decía dar a luz un libro, y, por haberlo escrito así, uno de nosotros perdió el curso de retórica (p. 3).

Sobre las cosas inmateriales, comúnmente llamadas metafísicas en tanto no se agrupan y dan cuenta mediante métodos propios de la física, también pensará Fernando González en su viaje. Si bien desde una teoría del conocimiento a los asuntos metafísicos también corresponden los asuntos de Dios y la fe, lo que se deja ver es la intencionalidad por recuperar su condición de un ser que es pensante de manera libre, que todo aquello que había sido asumido de una manera sumisa no era más que una estrategia, un período en su vida para identificar y conocer sobre los elementos teóricos de corte dogmático con los cuales habría de pelear siempre:

Ya ven los lectores a dónde nos llevarían los de la Juventud Católica si describiésemos a ese hermoso fruto de la serranía despojado de su corteza y de cara al sol naciente, 0 mejor dicho, de cara a las estrellas, y nosotros, según D'Annunzio, Chini sopra di lei come per bere d'un calice. Y, además, somos filósofos catos (González, 1995, p. 7).

En los tiempos de penuria -en la vejez-, recogemos en el regazo todo aquello de lo que en los bríos de nuestra juventud hemos renegado, peleado y maldecido: los ideales liberales, la renuncia y la no aceptación de lo tradicional y de una moral trasnochada, porque es de corte religioso, porque genera una confusión a la juventud, porque pone en evidencia que es una doble moral, la del sometimiento y la riqueza, la del amor y la injusticia. En este proceso liberador:

Necesitamos cuerpos, sobre otros cuerpos. Que no se tenga miedo al desnudo. A los colombianos, a este pobre pueblo sacerdotal, lo enloquece y lo mata el desnudo, pues nada que se quiera tanto como aquello que se teme. El clero ha pastoreado estos almácigos de zambos y patizambos y ha creado cuerpos horribles, hipócritas (González, 1995, p. 4).

Desnudarse es despojarse de las ataduras de la fe. En tiempos de descubrimiento y conquista, los evangelizadores españoles convirtieron en pecaminosa toda actividad natural y cotidiana de los indígenas, todo ritual que realizaban los indígenas a los dioses era tomado con un acto sacrílego y de origen demoníaco. Otro elemento subyugante que 
promulga la Iglesia Católica, es el repudio por nuestro cuerpo, en especial cuando este está desnudo, como se desarrolló en el tema de Amores, nunca desamores, las bellas formas son provocación, despiertan las más oscuras pasiones y las más ocultas perversiones, pero qué hace el hombre si esa es su naturaleza. La Iglesia Católica castra los ideales eróticos del hombre, manipula sus sentimientos, nubla la razón y genera pobreza económica y mental en los hombres, es conservadora y moralista, todos estos lastres con los que cargó González y de los que fue difícil desprenderse, fueron el pensar crítico sobre la realidad de su tiempo, acompañado de lecturas filosóficas las que posibilitaron cultivar los pensamientos de su espíritu libre, como lo plantea igualmente Gómez (2005):

... adopta la forma específica de un lenguaje acaso desconocido en su medio antioqueño y una rebeldía que es justo caracterizar como esencialmente conservadora. Su rebeldía conservadora, su resistencia polémica a la transformación de cuño burgués que vivió Medellín entre principios de siglo y finales de los veinte es la base social del mensaje extraño, entre provocativo y regresivo, de su inquietante obra (p. 367).

El autor no solo camina libre, sino que su cuerpo permite el acercamiento al precipicio existente entre el lenguaje y su propio ser; lugar en el que las relaciones de poder que se inyectan de libertad lo mantienen conectado con sus sentidos invitándolo a recorrer rutas escriturales inexploradas para la época; rutas que tomaron forma de camino, de creación, de desenfreno con forma de palabra, es en ese momento en el que el cuerpo se apodera del espacio y renace la libertad; como lo menciona Augé (1995): "Entonces sobre el cuerpo humano se desarrollarán los efectos de los cuales hablábamos a propósito de la construcción del espacio" (p. 67), González constantemente llega a su espacio, a su ruta, a su escritura, a su placer que conecta con su interior, con su crítica y su realidad literaria, como lo plantea González (2011):

... la narrativa que se crea a partir de él— se toma como un lugar de enunciación "adecuado y novedoso" por su cualidad de distanciamiento del centro social familiar, posibilitando que el viajero ejerza su capacidad de cuestionamiento, gracias precisamente a ese estar y sentirse por fuera de su lugar de origen. Es así como también la narrativa de viajes, gracias a su estructura autorreferencial, genera un espacio desde donde exponer y producir pensamientos, confrontando los estamentos de poder, problematizando diversos aspectos del presente cultural y social del país, y posibilitando un lugar de diálogo entre la narrativa de viajes y la situación por la que atraviesa el país (p. 90).

El cuestionamiento que se hace el autor en cada una de sus travesías, permite introducir al lector en ese permanente sentir, en ese deseo de narrar lo que sus ojos palpan, 
lo que sus manos acarician y llevan a disfrutar cada uno de esos viajes que emprende con el deseo de crear, escribir, imaginar, soñar.

\section{Conclusiones y convergencias}

A modo de síntesis, vemos cómo hay una variedad de temas e intencionalidades que se hacen evidentes en la obra de Fernando González, y cómo están presentes aspectos de orden político, religioso, político, social y cultural; lo que más llama la atención de González es la condición humana y cómo dicha condición es la sumatoria de sus modos de vida y los pensamientos que se comparten: "Lo airoso o desairado de la actitud humana depende de la ideología presente entonces en el campo de la conciencia. De ahí que aquellos que tienen gran movilidad de espíritu la sean también variadísimos en sus actitudes físicas" (González, 1995, p. 3).

Es así como desde el ideal de país, de sociedad que añora Fernando González, resaltan la pérdida de identidad, la ausencia de referentes comunes para el progreso, para el desarrollo, para ser libres.

Desde sus tiempos -tercera década del siglo XX-, Fernando González creía ver en las gentes que se encontraba a su paso, en sus largas caminatas, la pujanza del pueblo antioqueño, pero de igual manera, predestinaba una pérdida de ese liderazgo por lo conservador de las costumbres antioqueñas y en especial por la alta influencia que tenía $-\mathrm{y}$ tiene- la Iglesia Católica en el destino del pueblo antioqueño. Antioquia a finales del siglo XIX y comienzos del XX era grande, porque su pueblo y su gente eran grandes, y si no lo era, lo sabían demostrar muy bien. La clase dirigente del país amancebada con la Iglesia Católica, han cultivado una cultura dependentista y de subdesarrollo, para justificar la venta de las tierras, las empresas y la industria colombiana, pero los colombianos son un pueblo sin memoria y ahora le roban, le cambian su identidad y tampoco reacciona. González (1995) plantea:

Los que triunfan lo deben a una creencia arraigada, generalmente a la creencia en sí mismos. Son fracasados los que no han creído en algo que les sirviera de columna vertebral para desarrollar su personalidad; algunos, muy interesantes por cierto, creyeron fuertemente, pero la creencia se desvanecía para ser remplazada. Estos son aquellos de quienes se dice: "eran muy inteligentes y nada han realizado"; iqué inexplicable! (p. 9).

La corrupción política y la Iglesia Católica se convierten en los peores males para un país. Enmascaran su accionar en una doble moral, la iglesia y los políticos manejan una conciencia farisaica: solo lo que hacen los demás, el pueblo, es pecaminoso, es lesivo 
y corrupto, todo lo que hacen ellos simplemente era necesario hacerlo, lícito y para nada pecaminoso. Teniendo en frente la corrupción política y la religión como grandes males de la sociedad colombiana, González (1995) trae como ejemplo al indio Y:

... "No dejéis constancia escrita sino en último caso, para que no perdáis el crédito". Sí; el hombre cazador teme a la prueba preconstituida; teme a la prueba material. ¿Qué antiestético es todo lo petrificado! El indicio es una prueba elegante; con él se puede probar lo que se quiera, o sea: nada se puede probar; es indeterminado, como todo lo espiritual (p. 23).

Para esto hay que pensar en un nuevo tipo de hombre: uno que guste de ser libre, de ser feliz, pero no bajo el sometimiento de otro o hacia otro. En el amor, la política y en la diversidad de creencias, se está en condición de igualdad, por ley o por norma, se tienen los mismos derechos, los cuales se aplican bajo el principio de igualdad, reconociendo y respetando la divergencia y la diferencia.

González presenta su encuentro con lo desconocido, con el ambiente, dando inicio a su Viaje a pie, con lo espeso que lleva adentro, y lo denso y enigmático que está afuera a través de pautas corporales que emigran del mar interior del lenguaje, porque "El lenguaje lleva en sí mismo su principio interior de proliferación" (Foucault, 1984, p. 48) y escuchar el cuerpo y vivir en esa libertad constante en su escrito, permite que se desprenda paso a paso el ser oculto que hace sombra ante la palabra.

Para terminar este escrito y como inicio para futuros análisis, es válido decir "[...] el escritor envigadeño se adelantó a su tiempo no solo en la creación literaria, sino en el desnudamiento de las mentiras de nuestra sociedad y de nuestra cultura, que todavía persisten y requieren de nuevas confrontaciones ideológicas" (Ochoa Moreno, 1995, p. 99). Viaje a Pie de Fernando González desoculta la realidad colombiana que ha sido encerrada en la cadena de montañas antioqueñas. Como caminantes estamos llamados a disfrutar del aire puro, del verde de los valles y montañas, del aroma de nuestros jardines y bosques, pero como ciudadanos de a pie, estamos obligados a pensar de manera crítica sobre los problemas que agobian un país como Colombia. A cultivar espíritus libres y poder expresar libremente las ideas.

\section{Referencias}

Aristóteles. (1985). Obras completas - Del Alma, Ética Nicomaquea, Ética Eudemiana, PoéticaMadrid: Editorial Aguilar.

Augé, M. (1995). Los "No Lugares" Espacios del Anonimato: Una antropología de la sobremodernidad. Barcelona, España: Gedisa Ediorial, S.A 
Barthes, R. (1987). El Susurro del Lenguaje: Más allá de la palabra y de la escritura. Barcelona, España: Edición Paidós Ibérica, S.A.

Castellano Ascencio, M. (2013). Cortesía verbal y fórmulas de tratamiento nominales: Análisis pragmático de las fórmulas de tratamiento nominales en el habla de Medellín. Cuadernos de Lingüística Hispánica, (20), 41-56. Recuperado de: http://revistas.uptc.edu.co/index. php/linguistica_hispanica/article/view/464

Foucault, M. (1984). Las palabras y las cosas: una arqueología de las ciencias humanas. Barcelona: Planeta-Agostini.

Foucault, M. (1985). Saber y verdad. Madrid: Ediciones de la piqueta.

Gómez García, J. G. (2005). Literatura y sociedad: otro juicio sobre Tomás Carrasquilla, Fernando González y Sanín Echeverri. Ensayo sobre el proceso de masificación de Medellín. Boletín de Antropología Universidad de Antioquia, 19(36), 358-383.

González Ochoa, F. (1995). Viaje a pie. Medellín: Editorial Universidad de Antioquia.

González Otero, A. (2011). La literatura de viajes en Colombia. Una aproximación al género a través de dos libros de viaje a principios del siglo veinte: Viaje a pie de Fernando González y 4 años a bordo de mí mismo de Eduardo Zalamea. Cuadernos de Literatura, 15(29), 80-94.

Henao Hidrón, J. (1993). Fernando González, filósofo de la autenticidad. Medellín: Biblioteca Pública Piloto.

Macías Zuluaga, L. F. (1996). Diario de lectura II: El pensamiento estético en las obras de Fernando González. Medellín: Editorial Universidad de Antioquia.

Ochoa Moreno, E. (1995). Fernando González, actualidad y vigencia. Dyna, (119). Bogotá: Universidad Nacional de Colombia.

Peñuela Contreras, D. M. (2010). Fernando González, educador latinoamericano: pensamiento y rebeldía. Nómadas, (33), 199-210.

Pinto Saavedra, G. (1995). Fernando González y nosotros. Medellín: Concejo de Medellín.

Platón (1984). Diálogos -Apología de Sócrates, Banquete, Fedro-. México: Editorial Porrúa.

Villegas Botero, F. (1995). Fernando González, teólogo. Medellín: Concejo de Medellín. 